Prepared for the Machining Science and Technology

\title{
Effect of Additional Factors on Dimensional Accuracy and Surface
}

Finish of Turned Parts

M. N. Islam

Department of Mechanical Engineering,

Curtin University

Perth, WA 6845, Australia

Email: M.N.Islam@curtin.edu.au 


\section{Effects of Additional Factors on Dimensional Accuracy and Surface Finish of Turned Parts}

Abstract: This paper reports the experimental and analytical results of an investigation of additional factors that affect the dimensional accuracy and surface finish of turned parts besides the three major cutting parameters - cutting speed, feed rate, and depth of cut. The selected additional factors were cooling method, blank size, and work material. A three-level, three-parameter experiment was planned using design-of-experiment methodology. The three levels of independent input parameters were: for cooling method-dry turning, flood turning, and minimum quantity lubrication turning; for blank size $-\phi 20,40$, and $60 \mathrm{~mm}$; and for work material—aluminium 6061, mild steel 1030, and alloy steel 4340. The measured output parameters were the two most widely used dimensional accuracy characteristics of turned parts-diameter error and circularity - and the surface finish characteristic arithmetic average. The results were analysed applying three methods: traditional analysis, Pareto ANOVA, and Taguchi method. The results reveal that, while work material has the greatest effect on diameter error and surface roughness, the major contributor to circularity is blank size.

Keywords: dry turning, flood turning, minimum quantity lubrication (MQL) turning, blank size, Pareto ANOVA, Taguchi method 


\section{Introduction}

Several factors influence the dimensional accuracy and surface finish of turned parts. The most obvious ones are the three major cutting parameters-cutting speed, feed rate, and depth of cut. Consequently, most of the previous studies have focused on these three factors. However, in turning operations additional factors such as cooling method, blank size, and work material may also have significant effects on the quality of turned parts. The objective of this research is to explore these possibilities in detail.

Investigations of dimensional accuracies and surface finish of turned parts have received notable attention in the literature. A typical approach has been to study the effects of major cutting parameters on dimensional accuracy parameters such as diameter error and circularity and surface finish parameters such as arithmetic average $\left(\mathrm{R}_{\mathrm{a}}\right)$ and peak-to-valley height $\left(\mathrm{R}_{\mathrm{t}}\right)$ ) for various materials, such as free machining steel (Davim, 2001), aluminium-copper alloy (Marcos-B'arcena, 2005), chromium alloy tool steel SKD11 (Tzeng et al., 2009), maraging steel (Lalwani et al., 2008), composite materials (Manna and Bhattacharyya, 2002), chrome molybdenum steel SCM 400 (Thamizhmanii, 2007), mild steel 1030 (Nalbant et al., 2007), and alloy steel 4340 (Rafai and Islam, 2009). However, most of these studies are based on a single work material and as a result do not provide any indication of the effect of different materials on the dimensional accuracy and surface finish of turned parts.

Cutting fluids have been applied extensively in machining operations for the last 200 years for various reasons, such as to reduce friction and wear, hence improving tool life and surface finish; to reduce force and energy consumption; and to cool the cutting zone, thus reducing thermal distortion of the workpiece and improving tool life, and facilitating chip disposal. A body of literature investigating the effect of cutting fluid on dimensional accuracies and surface finish of machined parts has been published (Shaw, 1959; Heiman, 1966; De Chiffre, 1977; El Baradie, 1996; Upton, 1996; Avila and Abrao, 2001).

In recent years, a large number of studies have appeared in the literature to investigate the effects of cooling methods in turning operations with the aim of reducing the application of cutting fluids and their negative impact on the environment (Pusavec, 2011; Rafai and Islam, 2009; Jayal and Balaji, 2009; Marksberry and Jawahir, 2008; Lalwani, 2008; Sreejith, 2008; Sarma and Dixit, 2007; Kamat and Obikawa, 2007; Dhar 
et al., 2007; Bruni et al, 2006; Dhar et al., 2006; Dilbag et al., 2006; Varadaarajan et al, 2002; Klocke and Eisendlaetter, 1997; Wakabayashi, 1997). Accordingly, nontraditional forms of turning, such as dry turning, turning with minimum quantity lubrication (MQL), and cryogenic turning, gained renewed emphasis. A review of various cooling methods in turning operations can be found in Sharma et al. (2007).

A number of studies have presented comparisons among different types of cooling methods for turning operations. Varadaarajan et al. (2002) investigated hard turning of alloy steel 4340 with minimal cutting fluid application and compared the result with dry and wet turning in terms of various machining parameters such as cutting force, cutting temperature, cutting ratio, surface finish, tool life, and chip forms. Wanigarathne et al. (2003) presented an experimental investigation of machining with MQL of AISI 4140 alloy steel under a wide range of cutting conditions in terms of surface quality, chipform/chip breakability, and cutting force, and compared the result with those of dry and flood machining. Dhar et al. $\left(2006^{\mathrm{b}}\right)$ examined the influence of dry, flood, and MQL turning on tool wear and surface roughness in the turning of AISI 4340 steel. Dhar et al. (2007) also investigated the influence of dry, flood, and MQL turning on cutting temperature, chip formation, and associated diameter variation in the turning of AISI 1030 steel. Sreejith (2008) studied machining of 6061 aluminium alloy with dry, MQL, and flood turning with respect to cutting force, surface roughness, and tool wear. Marksberry and Jawahir (2008) developed a tool-wear/tool-life relationship model for near-dry machining (NDM) and applied their model in comparing the performance of NDM and dry machining of steel wheel rims in terms of tool wear and tool life. Rafai and Islam (2010) compared dry and flood turning of alloy steel AISI 4340 in terms of diameter error, circularity, and surface roughness. It is worth noting that while a large number of papers have appeared regarding the comparison of cooling methods on machinability characteristics such as cutting force, cutting power, and tool wear, only a few papers have been published on quality characteristics such as diameter error and circularity, even though both machinability and quality characteristics are equally important for successful machining operations. Surface finish falls under both categories and has appeared in several publications.

Blank size may also have a considerable effect on the dimensional accuracy and surface finish of turned parts due to its relationship with workpiece deflection and 
cooling efficiency. A predictive model for diameter error in bar turning of 1018 steel developed by Mayer et al. (2000) confirms this assumption. Hence, the main objectives of this research are to quantify the main and interaction effects of three input parameters - cooling method, blank size, and work material — on dimensional accuracy and the surface finish of turned parts, and to optimise their values.

\section{Scope}

The dimensional accuracy of turned parts is specified by a number of parameters; of these, diameter error and circularity are the two most important. Therefore, they were selected for this study. Diameter error is the difference between the measured diameter and the designed diameter, where a positive error indicates undercutting of a cylindrical workpiece. It is an important quality characteristic of turned component parts, especially when cylindrical fit is involved.

For turned parts, circularity (also known as roundness or out-of-roundness) is another important quality characteristic that is geometric in nature. Circularity is defined by two concentric circular boundaries within which each circular element of the surface must lie (ASME 2009). It is particularly important for rotating component parts where excessive circularity values may cause unacceptable vibration and heat.

Surface finish is another critical parameter that is of great importance from the viewpoint of wear, corrosion, fatigue, noise, load-carrying capacity, heat transfer, and many others. Surface roughness represents the random and repetitive deviations of a surface profile from the nominal surface. It can be expressed through a number of parameters; however, no single parameter appears to be capable of adequately describing the surface quality. In this study, arithmetic average was adopted to represent surface roughness, as it is the most frequently used and internationally accepted parameter.

The results were analysed applying three techniques - traditional analysis, Pareto analysis of variation (ANOVA), and Taguchi's signal-to-noise $(\mathrm{S} / \mathrm{N})$ ratio analysis. In traditional analysis, the mean values of the responses have been used. This tool is particularly suitable for monitoring a trend of change in the relationship of variables. However, it does not provide the complete picture, as it normally does not include data on scatter of the responses. 
Pareto ANOVA is an excellent tool for determining the contribution of each input parameter and their interactions with the output parameters (dimensional accuracy and surface finish characteristics). It is a simplified ANOVA analysis method that does not require an ANOVA table and does not use F-tests. Therefore, it does not require detailed knowledge about the ANOVA method. Further details on Pareto ANOVA are available in Park (1996).

The Taguchi method applies signal-to-noise $(S / N)$ ratio to optimize the outcome of a manufacturing process. The $\mathrm{S} / \mathrm{N}$ ratio can be calculated using the following formula (Ross, 1988):

$$
S / N=-10 \log \frac{1}{n}\left(\sum_{i=1}^{n} y_{i}^{2}\right)
$$

where $n$ is the number of observations and $y$ is the observed data.

The above formula is suitable for quality characteristics in which the adage 'the smaller the better' holds true. All three quality characteristics considered fall under this category. The higher the value of the $\mathrm{S} / \mathrm{N}$ ratio, the better the result is, because it guarantees the highest quality with minimum variance. A thorough treatment of the Taguchi method can be found in Ross (1988).

There is a wide range of materials available for turning operations. This study was limited to three materials - aluminium (AISI 6061), mild steel (AISI 1030), and alloy steel (AISI 4340). Some important properties and chemical compositions of the work materials compiled from Matweb (2011) are listed in Tables 1 and 2, respectively. These materials were purposely selected for their varying machinability properties and extensive applications in industry.

\section{Experimental work}

The experiments were planned using Taguchi's orthogonal array, and a three-level three-parameter $\mathrm{L}_{27}\left(3^{13}\right)$ orthogonal array was selected for our experiments. A copy of $\mathrm{L}_{27}\left(3^{13}\right)$ array is available in Taguchi (1987). A total of 27 parts were produced, nine parts each of three materials: aluminium (AISI 6061), mild steel (AISI 1030), and alloy steel (AISI 4340). The nominal size of each part was $160 \mathrm{~mm}$ length and $40 \mathrm{~mm}$ 
diameter. The experiment was carried out on a Harrison conventional lathe with 330 mm swing under constant cutting parameters for all parts: $150 \mathrm{~m} / \mathrm{min}$ cutting speed, $0.22 \mathrm{~mm} / \mathrm{rev}$ feed rate, and $1 \mathrm{~mm}$ depth of cut. The depth of cut value was chosen taking into consideration the finishing operation for which dimensional accuracy and surface finish are more relevant. The reason for adopting the same cutting parameters is to nullify their effects.

For holding the workpiece, a three-jaw chuck supported at dead centre was employed. Square-shaped inserts with enriched cobalt coating (CVD TiN-TiCN-Al $\mathrm{O}_{3}-\mathrm{TiN}$ ) manufactured by Stellram, USA, were used as the cutting tools. The inserts were mounted on a standard PSDNN M12 tool holder, which resulted in the following angles: $7^{\circ}$ clearance angle, $-7^{\circ}$ rake angle, $-6^{\circ}$ cutting edge inclination angle, and $45^{\circ}$ cutting edge angle. A new cutting tip was used for machining each part to avoid any tool wear effect.

For flood turning, Castrol Clearedge EP690, a semi-synthetic soluble cutting fluid, was applied at a flow rate of 0.43 1/sec. For MQL operation, 2010 Coolube, a vegetablebased metal cutting lubricant, was sprayed in mist form at $1.667 \times 10^{-5} 1 / \mathrm{sec}$ flow rate by a Uni-Max cutting tool lubrication delivery system, manufactured by Unist, U.S.A.

The precision measurements were taken by a Discovery Model D-8 coordinate measuring machine $(\mathrm{CMM})$, manufactured by Sheffield, UK. The probes used were spherical probes with a star configuration, manufactured by Renishaw Electrical Ltd., UK. The diameters of the test parts were determined using the standard built-in software package of the CMM. Eight points were measured for each measurement of diameter, and each measurement was repeated three times. The circularity data was also obtained from the CMM. The surface roughness parameter arithmetic average $\left(R_{a}\right)$ for each turned surface was determined by a surface-measuring instrument, the Surftest SJ-201P, manufactured by Mitutoyo, Japan.

\section{Results and Analysis}

An enormous amount of data were obtained and subsequently analysed. Due to space constraints, only a few are presented, although in the analysis of the work all of these relationships were considered at different stages. Because of the multi-variability of data, it is possible to present them in a number of ways. The adopted format was chosen 
carefully to maximise the clarity of the presentation. Experimental results for diameter error, circularity, surface roughness, and their corresponding $\mathrm{S} / \mathrm{N}$ ratios are summarised in Table 3.

\subsection{Diameter Error}

The Pareto ANOVA analysis for diameter error given in Table 4 demonstrates that work material (C) has the most significant effect on diameter error with a contribution ratio $(\mathrm{P} \cong 54 \%)$, followed by cooling method $(\mathrm{A})(\mathrm{P} \cong 11 \%)$, and blank diameter $(\mathrm{B})(\mathrm{P}$ $\cong 4 \%)$. The interaction between blank size and work material $(B \times C)$ also played a role ( $\mathrm{P} \cong 12 \%)$. It is worth pointing out that the total contribution of the main effects is about $70 \%$, compared to the total $30 \%$ contribution of the interaction effects, thus making it moderately difficult to optimise the diameter error by selection of input parameters.

The response table and response graphs for diameter error are presented in Table 5 and Figure 1, respectively. As the slopes of the response graphs represent the strength of contribution, the response graphs confirm the findings of the Pareto ANOVA analysis given in Table 4. Table 5 shows that a high level of cooling method $\left(\mathrm{A}_{2}\right)$ is the best combination. Because the interaction $\mathrm{B} \times \mathrm{C}$ was significant, a $\mathrm{B} \times \mathrm{C}$ two-way table was applied to select their levels. The two-way table is not included in this paper due to space constraints. From the $\mathrm{B} \times \mathrm{C}$ two-way table, the optimum combination of factors $\mathrm{B}$ and $\mathrm{C}$ in order to achieve the lowest diameter error was determined as $\mathrm{B}_{0} \mathrm{C}_{1}$. Thus, the best combination of input variables for minimising diameter error was determined as $\mathrm{A}_{2} \mathrm{~B}_{0} \mathrm{C}_{1}$; i.e. high level of cooling method (MQL), low level of blank size (20 mm), and medium level of work material (mild steel AISI 1030).

The traditional analyses for diameter error are presented in Figures 2 and 3, where Figure 2 shows the actual variation of diameter error for the three additional parameters and Figure 3 shows the average variation of diameter error. As diameter errors can be both positive and negative (see Figure 2), the average diameter error is expressed in absolute values in Figure 3. The dominant effect of work material on diameter error is evident from Figure 3, which conforms to the finding of Pareto ANOVA analysis given in Table 4.

Figure 2 shows that, in low and high blank size ranges, the difference in diameter error for all three materials considered is insignificant, although in general, mild steel 
produced the best result, followed by aluminium and alloy steel. In the mid-blank size range, however, the difference is higher, and aluminium generated the best diameter error, followed by mild steel and alloy steel. It is worth noting that, in this range, parts made of aluminium produced overcut (negative diameter error), whereas mild steel and alloy steel produced undercut (positive diameter error), which is believed to be associated with the hardness of work material. The harder the material, the less is the overcut.

Analysis of Figure 3 leads to the similar conclusion reached through the Taguchi method, i.e. high level of cooling method (MQL), low level of blank size (20 mm), and medium level of work material (mild steel AISI 1030) produced the best result.

\subsection{Circularity}

The Pareto ANOVA analysis for circularity given in Table 6 shows that blank size (B) has the most significant effect on circularity with a contribution ratio ( $\mathrm{P} \cong 38 \%$ ), followed by cooling method $(\mathrm{A})(\mathrm{P} \cong 7 \%)$ and work material $(\mathrm{C})(\mathrm{P} \cong 4 \%)$. The interactions between cooling method and blank size $(\mathrm{A} \times \mathrm{C})$ and between blank size and work material $(\mathrm{B} \times \mathrm{C})$ also played roles, with a contribution of $12.53 \%$ and $10.60 \%$, respectively. The total contribution of the main effects is about $49 \%$, compared to the total contribution of the interaction effects of $51 \%$, thus making it highly difficult to optimise the circularity error by selection of input parameters.

The response table and response graphs for circularity are presented in Table 7 and Figure 4, respectively. The response graphs confirm the findings of the Pareto ANOVA analysis given in Table 6 . Table 7 shows that high level of blank size $\left(B_{2}\right)$ is the best combination. Because the interaction $\mathrm{A} \times \mathrm{C}$ was significant, an $\mathrm{A} \times \mathrm{C}$ two-way table was applied to select their levels. From the $\mathrm{A} \times \mathrm{C}$ two-way table, the optimum combination of factors $\mathrm{A}$ and $\mathrm{C}$ in order to achieve the best surface roughness value was determined as $\mathrm{A}_{2} \mathrm{C}_{0}$. Thus, the best combination of input variables for minimising circularity was determined as $\mathrm{A}_{2} \mathrm{~B}_{2} \mathrm{C}_{0}$; i.e. high level of cooling method (MQL), high level of blank size $(60 \mathrm{~mm})$, and low level of work material (aluminium AISI 6061).

The tradition analyses for circularity are presented in Figures 5 and 6, where Figure 5 shows the actual variation of circularity for the three additional parameters and Figure 6 shows the average variation of circularity. Figure 5 shows that, for all three work 
materials considered, the high level of blank size $(60 \mathrm{~mm})$ produced the best result. Results for $20 \mathrm{~mm}$ and $40 \mathrm{~mm}$ were inconclusive. Analysis of Figure 6 leads to the similar conclusion reached through the Taguchi method, i.e. high level of cooling method (MQL), high level of blank size $(60 \mathrm{~mm})$, and low level of work material (aluminium AISI 6061) produced the best result.

\subsection{Surface Roughness}

The Pareto ANOVA analysis for surface roughness given in Table 8 illustrates that work material (C) has the most significant effect on surface roughness with a contribution ratio $(\mathrm{P} \cong 64 \%)$, followed by cooling method $(\mathrm{A})(\mathrm{P} \cong 10 \%)$, and blank size (B) $(\mathrm{P} \cong 6 \%)$. The interactions between cooling method and work material $(\mathrm{A} \times \mathrm{B})$ and between blank size and work material $(\mathrm{B} \times \mathrm{C})$ also played roles, with a contribution of $6.58 \%$ and $6.18 \%$ respectively. The total contribution of main effects is about $79 \%$ compared to the total contribution of the interaction effects of $21 \%$, thus making it relatively easier to optimise the surface roughness in this instance by selection of input parameters.

The response table and response graphs for surface roughness are presented in Table 9 and Figure 7, respectively. The response graphs confirm the findings of the Pareto ANOVA analysis given in Table 8 . Table 9 shows that low level of work material $\left(\mathrm{C}_{0}\right)$ is the best combination. Because the interaction $\mathrm{A} \times \mathrm{B}$ was significant, an $\mathrm{A} \times \mathrm{B}$ two-way table was applied to select their levels. From the $\mathrm{A} \times \mathrm{B}$ two-way table, the optimum combination of factors $\mathrm{A}$ and $\mathrm{B}$ in order to achieve the best surface roughness value was determined as $\mathrm{A}_{2} \mathrm{~B}_{1}$. Thus, the best combination of input variables for minimising surface roughness was determined as $A_{2} B_{1} C_{0}$; i.e. high level of cooling method (MQL), medium level of blank size (40 mm), and low level of work material (aluminium AISI 6061).

Variation in surface roughness for the three input parameters is presented in Figure 8. The graph shows that, for all of the three work materials considered, aluminium produced the best result, followed by alloy steel and mild steel. In the low blank size range, the difference between the surface roughness of mild steel and aluminium is negligible, whereas in the remaining blank size ranges the differences are comparatively high. The surface roughness of mild steel was the worst by large margins among the 
three materials considered, in all blank size ranges, followed by mild steel and aluminium. The graph also reveals that the surface roughness for different materials is influenced differently by cooling method, and in almost all cases the best surface roughness was achieved by MQL.

\section{Discussion}

Analyses of results presented above indicate that the additional factors - cooling method, blank size, and work material—demonstrated considerable effects on diameter error and circularity (Figures 3 and 6), whereas the effect on surface roughness was relatively low (Figures 9). The reason behind this is that the main factor influencing surface roughness is feed rate, which was kept constant for all experimental runs. Of the three additional factors considered, work material showed the highest contribution (Figures 7 and 9; Tables 8 and 9).

Figures 3, 6, and 9 reveal that of the three cooling methods considered, MQL produced the best results for all three quality characteristics. In addition, this is true in the majority of cases when considered on a case-by-case basis (Figures 2, 5, and 8). Response graphs given in Figures 1, 4, and 7 show that MQL $\left(\mathrm{A}_{2}\right)$ was the best cooling method for all three quality characteristics. This better performance of MQL turning has been reported by a number of researchers, in terms of both machinability characteristics (Varadaarajan et al., 2002; Wanigarathne et al., 2003) and quality characteristics (Dhar, $\left.2006^{\mathrm{a}}\right)$.

Among the three cutting parameters - cutting speed, feed rate, and depth of cutcutting speed is the main contributor to diameter error (Rafai and Islam 2009). Cutting speed is known to affect diameter error in a number of ways, such as by changing elastic deformation of the workpiece induced by the change in cutting force, by tool wear, by increasing thermal distortion, by formation of a built-up edge (BUE), and by increasing radial spindle error. In the present study, the most likely cause for the change in diameter error was the change of elastic deformation of the workpiece, which depends on the cutting force and the modulus of the elasticity of the material; both have a strong relationship with the work material (C). Hence, work material (C) showed the highest effect (Table 4). However, the net effect of work material on diameter error due to workpiece deflection is difficult to predict, because with the increase in hardness the 
cutting force is increased, which increases the workpiece deflection, resulting in higher diameter error. But in general, the modulus of elasticity also increases with the increase in hardness (see Table 2), which should reduce workpiece deflection. Elastic deformation is also influenced by blank size, which explains the strong interaction between blank size and work material $(B \times C)$, shown in Table 4 .

Rafai and Islam (2009) attributed the primary cause of circular error to an overcut of material opposite the position of each jaw of the three-jaw chuck, and an undercut of material along the position of each jaw. This is believed to be caused by variation in stiffness of the workpiece cross-section due to varying directions of the radial cutting force with respect to the jaw positions. Radial stiffness is significantly influenced by blank size and work material. This elucidates a high contribution blank size (B) and interaction effect of blank size and work material $(B \times C)$ on circularity (Table 8$)$. This also explains the best performance of high level of blank size $\left(B_{2}\right)$ in Figures 4-6.

Figure 8 demonstrates that, contrary to traditional machining wisdom, the material with the higher machinability rating did not always produce a better surface finish, and therefore surface roughness by itself is not a reliable indicator of machinability. The reason behind this is that the optimum cutting conditions for various materials are different; in our experiment we selected the same cutting conditions for all the materials selected, conservatively based on the optimum cutting condition suitable for the material most difficult to machine, alloy steel AISI 4340, primarily to protect the tool. Furthermore, due to the interaction effects of the additional factors as shown in Table 8, surface roughness is not always related to machinability rating.

In addition to the three major cutting parameters - cutting speed, feed rate, and depth of cut - there are a number of other factors that may influence the dimensional accuracy and surface finish of turned parts, such as work material, tool material, tool geometry, and machine condition. Through the research presented in this paper it has been shown that the three additional factors considered-cooling method, blank sizes, and work material-have significant effects on the quality characteristics. Therefore, future studies should take additional factors into account to ensure that the results can be applied meaningfully. 


\section{Conclusions}

From the experimental work conducted and the subsequent analysis, the following conclusions can be drawn:

- Additional factors-cooling method, blank size, and work material-have demonstrated considerable effects on the dimensional accuracy characteristics, diameter error and circularity, whereas the effect on surface roughness was relatively low.

- The results reveal that while the work material has the greatest effect on diameter error and surface finish, the major contributor to circularity is blank size.

- Surface roughness by itself is not a reliable indicator of machinability, due to nonoptimal cutting conditions and interaction effects of additional factors.

- Dimensional accuracy and surface roughness of different work materials are influenced differently by the cooling methods, and in most cases the best result was achieved by MQL. Further research is needed to fully understand the cooling mechanism of MQL on the dimensional accuracy and surface finish of different materials.

\section{Acknowledgement}

The author would like to acknowledge the contribution of Mr. M. T. Marwan, a Master of Engineering student at the Department of Mechanical Engineering, Curtin University, Australia.

\section{References}

Aliva, R.F.; Abrao, A.M. (2001) The Effect of Cutting Fluids on The Machining of Hardened AISI 4340 Steel, Journal of Materials Processing Technology, 119: 2126.

ASME (2009) ASME Y14.5-2009, Dimensioning and Tolerancing, ASME, New York.

Bruni, C.; Forcellese, F.; Gabrielli, F.; Simoncini, M. (2006) "Effect of the Lubricationcooling Technique, Insert Technology and Machine Bed Material on the Workpart Surface Finish and Tool Wear in Finish Turning of AISI 420B”, Int. J. Mach. Tools \& Manuf., Vol. 46, pp.1547-1554. 
De Chiffre, L. (1977) Mechanics of Metal Cutting and Fluid Action, Int. J. of Machine Tool design and Research, 17 (4): 225-234.

Dhar, N.R.; Ahmed, M.T.; Islam, S. (2007) An Experimental Investigation on Effect of Minimum Quality Lubrication in Machining AISI 1040 Steel”, Int. J. Mach. Tools \& Manuf., Vol. 47, pp.748-753.

Dhar, N.R.; Islam, M.W; Islam, S.; Mithu, M.A.H. (2006 $)$ The influence of minimum quality lubrication (MQL) on cutting temperature, chip and dimensional accuracy in turning AISI-1040 steel, Journal of Materials Processing Technology, 171: 9399.

Dhar, N.R.; Kamruzzaman, M.; Ahmed, M. (2006 $)$ Effect of minimum quantity lubrication (MQL) on tool wear and surface roughness in turning AISI-4340 steel, Journal of Materials Processing Technology, 172: 299-304.

Davim, J.P. (2001) A Note on the determination of optimal cutting conditions for surface finish obtained in turning using design of experiments, Journal of Materials Processing Technology, 116: 305-308.

El Baradie (1996) Cutting Fluids: Part 1. Characterisation, Journal of Materials Processing Technology, 66: 786:797.

Heiman, D.K. (1966) Cutting Fluid, US Patent 3,265,620: 1-6

Jayal, A.D.; Balaji, A.K. (2009) "Effects of Cutting Fluid Application on Tool Wear in Machining: Interactions with Tool-coatings and Tool Surface Features, Wear, 269: $1723-1730$.

Kamat, Y.; Obikawa, T. (2007) High Speed MQL Finish-turning of Inconel 718 with Different Coated Tools, J. Materials Processing Technology, Vol. 192-193, pp. 281-286.

Klocke, F.; Eisendlaetter, G. (1997) Dry Cutting, CIRP Annals - Manufacturing Technology, 46 (2): 519-526.

Lalwani, D.I.; Mehta N.K.; Jain P.K. (2008) Experimental investigations of cutting parameters influence on cutting forces and surface roughness in finish hard turning of MDN250 steel, Journal of Materials Processing Technology, 206: 167179. 
Manna, A.; Bhattacharyya, B. (2002) A study on different tooling system during machining of Al/SiC-MMC, Journal of Materials Processing Technology, 123: 476-481.

Marcos-Bárcena, M.; Sebastián-Pérez, M.A.; Contreras-Samper, J. P.; SánchezCarrilero, M.; Sánchez-López,M.; Sánchez-Sola J.M. (2005) Study of roundness on cylindrical bars turned of aluminium-copper alloys UNS A92024. Journal of Materials Processing Technology 162-163: 644-648.

Marksberry, P.W.; Jawahir, I.S. (2008) A Comprehensive Tool-wear/Tool-life Model in the Evaluation of NDM (Near Dry Machining) for Sustainable Manufacturing", Int. J. Mach. Tools \& Manuf., 48: 878-886.

Matweb (2011), Material Property Data, Accessed through Internet (25/4/2011), http://www.matweb.com/

Nalbant, M.; Gokkaya, H.; Sur, G. (2007) Application of Taguchi Method in the Optmization of Cutting Parameters for Surface Roughness in Turning, Materials and Design, 28: 1379-1385Pusavec, F.; Hamdi, H.; Kopac, J.; Jawahir, I.S. (2011) “Surface Integrity in Cryogenic Machining of Nickel Based Alloy-Inconel 718”, Journal of Materials Processing Technology, 211: 773-783.

Park, S.H. (1996) Robust Design and Analysis for Quality Engineering, Chapman \& Hall, London.

Rafai, N. H.; Islam M. N. (2010) Comparison of Dry and Flood Turning in Terms of Quality of Turned Parts, Proc. World Congress on Engineering 2010, June $30^{\text {th }}-$ July $2^{\text {nd }}, 2010$, London, pp. 2044-2049.

Rafai, N. H.; Islam, M. N. (2009) An Investigation into Dimensional Accuracy and Surface Finish Achievable in Dry Turning, Machining Science and Technology, 13: $571-589$.

Ross, P.J. (1988) Taguchi Techniques for Quality Engineering, McGraw-Hill, New York.

Sharma, D.K.; Dixit, U.S. (2007) A comparison of dry and air-cooled turning of grey cast iron with mixed oxide ceramic tool, Journal of Materials Processing Technology, 190: 160-172. 
Sharma, V.S.; Dogra, M.; Suri, N.M. (2009) Cooling techniques for improved productivity in turning, International Journal of Machine Tool and Manufacture, 49: 435-453.

Shaw, M.C. (1959) On the Action of Metal Cutting Fluids at Low Speeds, Wear, 2 (3): 217-227.

Sreejith, P.S. (2008) "Machining of 6061 Aluminum Alloy with MQL, Dry and Flooded Lubricant Conditions”, Materials Letters, 62: 276-276.

Taguchi, G. (1987) System of Experimental Design: Engineering Methods to Optimize Quality and Minimize Cost, Vol. 2, UNIPUB/Kraus Int. Pub., White Plains, NY.

Thamizhmanii, S.; Saparudin, S.; Hasan, S. (2007) Analyses of surface roughness by turning process using Taguchi method, Journal of Achievements in Materials and Manufacturing Engineering, 20: 503-506.

Tzeng C-J.; Lin, Y-H., Yang, Y-R; Jeng, M-C. (2009) Optimization of turning operations with multiple performance chracterisics using the Taguchi method and Grey relational analysis, Journal of Materials Processing Technology 209: 27532759.

Upton, D.P. (1996) An Assessment of Cutting Fluid Performance and Improvements in Surface Finish, Transactions of the Institute of Metal Finishing, 74 (3): 103-105.

Varadaarajan, A.S., Philip, P.K. Ramamoorthy, B. (2002) Investigations on hard turning with minimal cutting fluid application (HTMF) and its comparison with dry and wet turning", International Journal of Machine Tool and Manufacture, 42: 193200.

Wakabayashi, T.; Sato, H.; Insaki, I. (1997) Turning Using Extremely Small Amount of Cutting Fluid, JSME International Journal, 41 (1): 488-493.

Wanigarathne, P.C.; Ee, K.C.; Jawahir, I.S. (2003) Near-dry machining for environmentally benign manufacturing - A comparison of machining Performance with flood cooling and dry machining, Hon, B. (Eds), Design and Manufacture for Sustainable Development, Professional Engineering Publ., pp. 39-48. 
Table 1: Properties of Work Materials (Matweb, 2011)

\begin{tabular}{lcrrr}
\hline \hline Properties & Unit & AISI 6061 & AISI 1030 & AISI 4340 \\
\hline Machinability & $\%$ & 1190 & 71 & 50 \\
Hardness & $\mathrm{BH}$ & 95 & 149 & 217 \\
Modulus of elasticity & $\mathrm{Gpa}$ & 68.9 & 205 & 205 \\
Specific heat capacity & ${\mathrm{J} / \mathrm{g}^{\circ} \mathrm{C}}^{\prime}$ & 0.896 & 0.486 & 0.475 \\
\hline \hline
\end{tabular}

Table 2: Chemical Compositions of Work Materials (Matweb, 2011)

\begin{tabular}{|c|c|}
\hline \multicolumn{2}{|c|}{ AISI 6061} \\
\hline Aluminium, Al & $95.8-98.6 \%$ \\
\hline Chromium, $\mathrm{Cr}$ & $0.040-0.35 \%$ \\
\hline Copper, Cu & $0.15-0.40 \%$ \\
\hline Iron, Fe & $\leq 0.70 \%$ \\
\hline Magnesium, Mg & $0.80-1.20 \%$ \\
\hline Manganese, Mn & $\leq 0.15 \%$ \\
\hline Other, each & $\leq 0.050 \%$ \\
\hline Other, total & $£ 0.15 \%$ \\
\hline Silicon, Si & $0.40-0.80 \%$ \\
\hline Titanium, Ti & $\leq 0.15 \%$ \\
\hline Zinc, Zn & $\leq 0.25 \%$ \\
\hline \multicolumn{2}{|c|}{ AISI 1030} \\
\hline Carbon, C & $0.270-0.340 \%$ \\
\hline Iron, Fe & $98.67-99.13 \%$ \\
\hline Manganese, Mn & $0.60-0.90 \%$ \\
\hline Phosphorous, P & $\leq 0.040 \%$ \\
\hline Sulfur, S & $\leq 0.050 \%$ \\
\hline \multicolumn{2}{|c|}{ AISI 4340} \\
\hline Carbon, C & $0.370-0.430 \%$ \\
\hline Chromium, $\mathrm{Cr}$ & $0.700-0.900 \%$ \\
\hline Iron, Fe & 95.195 - $96.33 \%$ \\
\hline Manganese, Mn & $0.600-0.800 \%$ \\
\hline Molybdenum, Mo & $0.200-0.300 \%$ \\
\hline Nickel, Ni & $1.65-2.00 \%$ \\
\hline Phosphorous, P & $\leq 0.0350 \%$ \\
\hline Silicon, Si & $0.150-0.300 \%$ \\
\hline Sulfur, S & $\leq 0.0400 \%$ \\
\hline
\end{tabular}


Table 3: Experimental Results for Diameter Error, Circularity, Surface Roughness, and Their Corresponding S/N Ratios

\begin{tabular}{|c|c|c|c|c|c|c|}
\hline \multirow[b]{2}{*}{$\begin{array}{l}\text { Experimental } \\
\text { run }\end{array}$} & \multicolumn{3}{|c|}{ Measured parameters } & \multicolumn{3}{|c|}{ Calculated $\mathrm{S} / \mathrm{N}$ ratio } \\
\hline & $\begin{array}{c}\text { Diameter } \\
\text { error } \\
(\mathrm{mm}) \\
\end{array}$ & $\begin{array}{c}\text { Circularity } \\
(\mu \mathrm{m})\end{array}$ & $\begin{array}{c}\text { Surface } \\
\text { roughness } \\
(\mu \mathrm{m})\end{array}$ & $\begin{array}{c}\text { S/N ratio } \\
\text { for } \\
\text { diameter } \\
\text { error }\end{array}$ & $\begin{array}{l}\text { S/N ratio } \\
\text { for } \\
\text { circularity }\end{array}$ & $\begin{array}{l}\text { S/N ratio } \\
\text { for } \\
\text { surface } \\
\text { roughness }\end{array}$ \\
\hline 1 & 0.20 & 17.33 & 1.88 & 13.62 & 35.06 & -5.49 \\
\hline 2 & 0.00 & 9.67 & 2.60 & 25.04 & 40.16 & -8.31 \\
\hline 3 & 0.19 & 9.00 & 1.92 & 14.10 & 40.92 & -5.66 \\
\hline 4 & -0.03 & 8.33 & 1.56 & 29.00 & 41.53 & -3.86 \\
\hline 5 & 0.04 & 23.33 & 2.28 & 26.21 & 32.51 & -7.17 \\
\hline 6 & 0.23 & 11.33 & 1.77 & 12.77 & 38.73 & -4.98 \\
\hline 7 & 0.29 & 4.33 & 1.93 & 10.74 & 47.21 & -5.71 \\
\hline 8 & 0.05 & 9.00 & 2.27 & 25.78 & 40.81 & -7.13 \\
\hline 9 & 0.16 & 8.33 & 2.11 & 16.05 & 41.10 & -6.47 \\
\hline 10 & 0.10 & 18.00 & 1.75 & 19.34 & 34.89 & -4.86 \\
\hline 11 & 0.00 & 10.00 & 2.18 & 25.83 & 39.97 & -6.76 \\
\hline 12 & 0.17 & 11.00 & 1.75 & 15.18 & 38.37 & -4.87 \\
\hline 13 & -0.17 & 7.33 & 1.65 & 15.28 & 42.62 & -4.36 \\
\hline 14 & 0.08 & 11.00 & 2.30 & 21.44 & 39.15 & -7.24 \\
\hline 15 & 0.65 & 7.67 & 2.22 & 3.69 & 42.19 & -6.93 \\
\hline 16 & 0.16 & 5.33 & 1.90 & 15.86 & 45.23 & -5.59 \\
\hline 17 & 0.11 & 9.00 & 2.43 & 18.80 & 40.51 & -7.73 \\
\hline 18 & 0.29 & 7.33 & 2.14 & 10.85 & 42.47 & -6.60 \\
\hline 19 & -0.03 & 7.67 & 1.73 & 24.42 & 42.24 & -4.75 \\
\hline 20 & -0.07 & 8.67 & 1.99 & 21.31 & 41.15 & -5.99 \\
\hline 21 & 0.01 & 7.67 & 1.85 & 24.51 & 42.29 & -5.34 \\
\hline 22 & -0.11 & 9.33 & 1.59 & 18.84 & 40.56 & -4.05 \\
\hline 23 & -0.03 & 6.67 & 1.97 & 28.20 & 43.50 & -5.90 \\
\hline 24 & 0.24 & 24.67 & 1.90 & 12.17 & 31.25 & -5.59 \\
\hline 25 & 0.14 & 5.00 & 1.69 & 17.06 & 45.91 & -4.54 \\
\hline 26 & 0.05 & 4.33 & 2.04 & 26.02 & 47.21 & -6.20 \\
\hline 27 & 0.16 & 7.00 & 1.97 & 15.80 & 42.87 & -5.89 \\
\hline
\end{tabular}


Table 4: Pareto ANOVA Analysis for Diameter Error

\begin{tabular}{|c|c|c|c|c|c|c|c|c|c|}
\hline \multirow{2}{*}{ Sum at factor level } & \multicolumn{9}{|c|}{ Factor and interaction } \\
\hline & $\mathbf{A}$ & B & $\mathbf{A x B}$ & AxB & C & AxC & AxC & BxC & BxC \\
\hline $\mathbf{0}$ & 173.33 & 183.36 & 157.48 & 152.06 & 164.17 & 158.62 & 171.91 & 156.61 & 175.94 \\
\hline 1 & 146.27 & 167.60 & 187.23 & 183.74 & 218.63 & 179.99 & 167.08 & 178.00 & 144.47 \\
\hline 2 & 188.32 & 156.97 & 163.21 & 172.13 & 125.13 & 169.31 & 168.93 & 173.31 & 187.51 \\
\hline Sum of squares of difference (S) & 2725.08 & 1057.72 & 1494.36 & 1541.34 & 13230.96 & 685.11 & 35.71 & 758.41 & 2977.31 \\
\hline \multirow[t]{2}{*}{ Contribution ratio (\%) } & 11.12 & 4.32 & 6.10 & 6.29 & 53.99 & 2.80 & 0.15 & 3.09 & 12.15 \\
\hline & 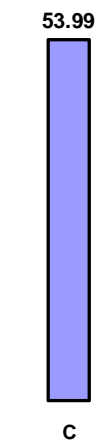 & $\stackrel{12.15}{2}$ & 11.12 & $\square_{\mathrm{A} \times \mathrm{B}}^{6.29}$ & ${ }_{\mathrm{A} \times \mathrm{B}}^{6.10}$ & $\square_{\mathrm{B}}^{4.32}$ & $\underset{B \times C}{\square .09}$ & ${ }_{\text {AxC }}^{2.80}$ & $\frac{0.15}{\mathrm{AxC}}$ \\
\hline Cumulative contribution & 53.99 & 66.14 & 77.26 & 83.36 & 87.67 & 97.06 & 97.06 & 99.85 & 100.00 \\
\hline \multirow{2}{*}{\multicolumn{3}{|c|}{$\begin{array}{l}\text { Check on significant interaction } \\
\end{array}$}} & \multicolumn{7}{|c|}{ BxC two-way table } \\
\hline & & & $\mathrm{A} 2 \mathrm{~B} 0 \mathrm{Cl}$ & & & & & & \\
\hline
\end{tabular}

Table 5: Response Table for Mean S/N Ratio for Diameter Error, and Significant Interaction

\begin{tabular}{lcrrrr}
\hline \hline & & \multicolumn{4}{c}{ Mean S/N ratio } \\
\cline { 3 - 6 } Input parameters & Symbol & Level 0 & Level 1 & Level 2 & Max-Min \\
\hline Cooling method & $\mathrm{A}$ & 19.26 & 16.25 & 20.92 & 1.67 \\
Blank size & $\mathrm{B}$ & 20.37 & 18.62 & 17.44 & 2.93 \\
Work material & $\mathrm{C}$ & 18.24 & 24.29 & 13.90 & 10.39 \\
Interaction BxC & $\mathrm{BxC}$ & 19.55 & 16.05 & 20.83 & 4.78 \\
\hline \hline
\end{tabular}


Table 6: Pareto ANOVA Analysis for Circularity

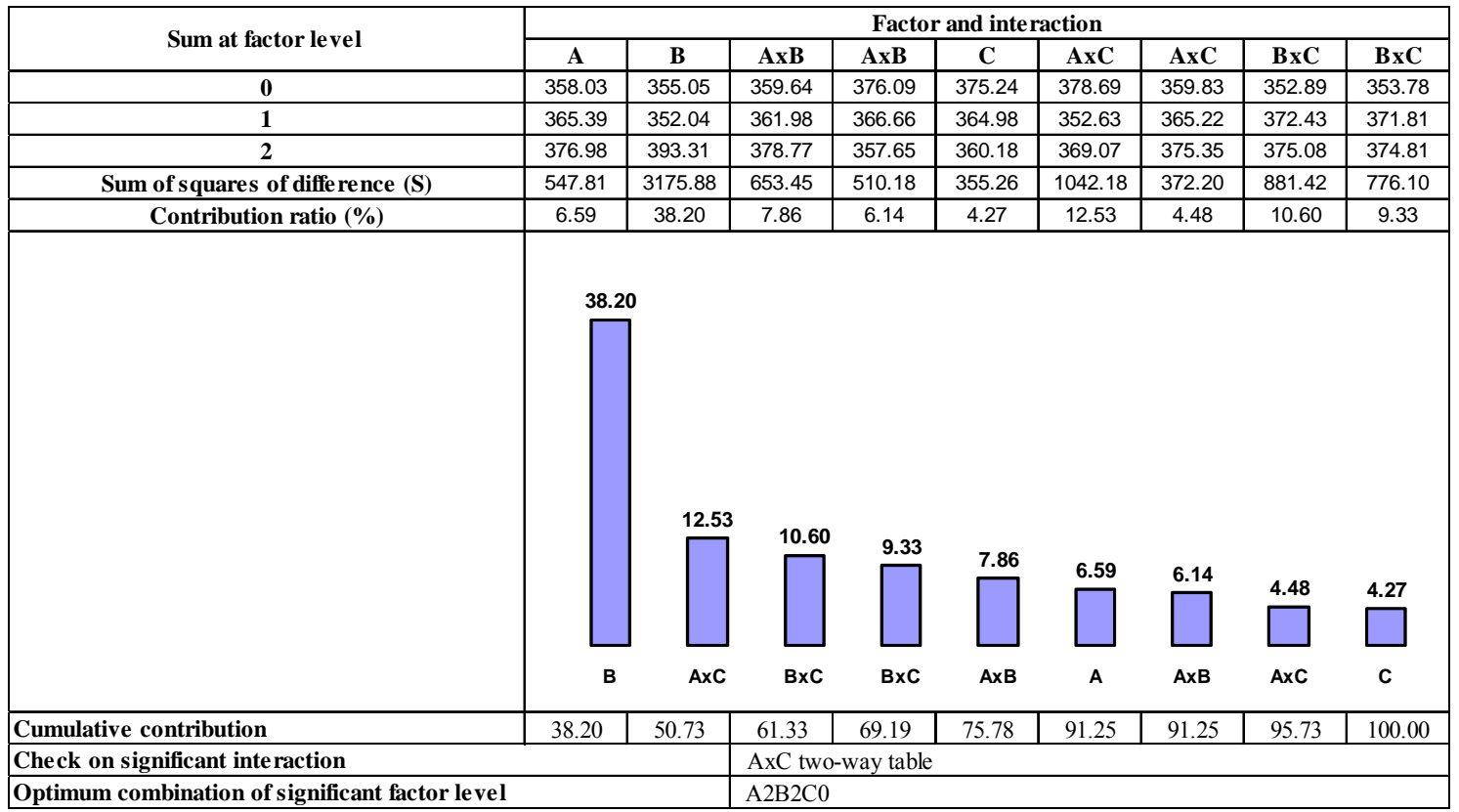

Table 7: Response Table for Mean S/N Ratio for Circularity, and Significant Interaction

\begin{tabular}{lcrrrr}
\hline \hline & & \multicolumn{3}{c}{ Mean S/N ratio } \\
\cline { 3 - 6 } Input parameters & Symbol & Level 0 & Level 1 & Level 2 & Max-Min \\
\hline Cooling method & $\mathrm{A}$ & 39.78 & 40.60 & 41.89 & 2.11 \\
Blank size & $\mathrm{B}$ & 39.45 & 39.12 & 43.70 & 4.59 \\
Work material & $\mathrm{C}$ & 41.69 & 40.55 & 40.02 & 1.67 \\
Interaction AxC & $\mathrm{AxC}$ & 42.08 & 39.18 & 41.01 & 2.90 \\
\hline \hline
\end{tabular}


Table 8: Pareto ANOVA Analysis for Surface Roughness

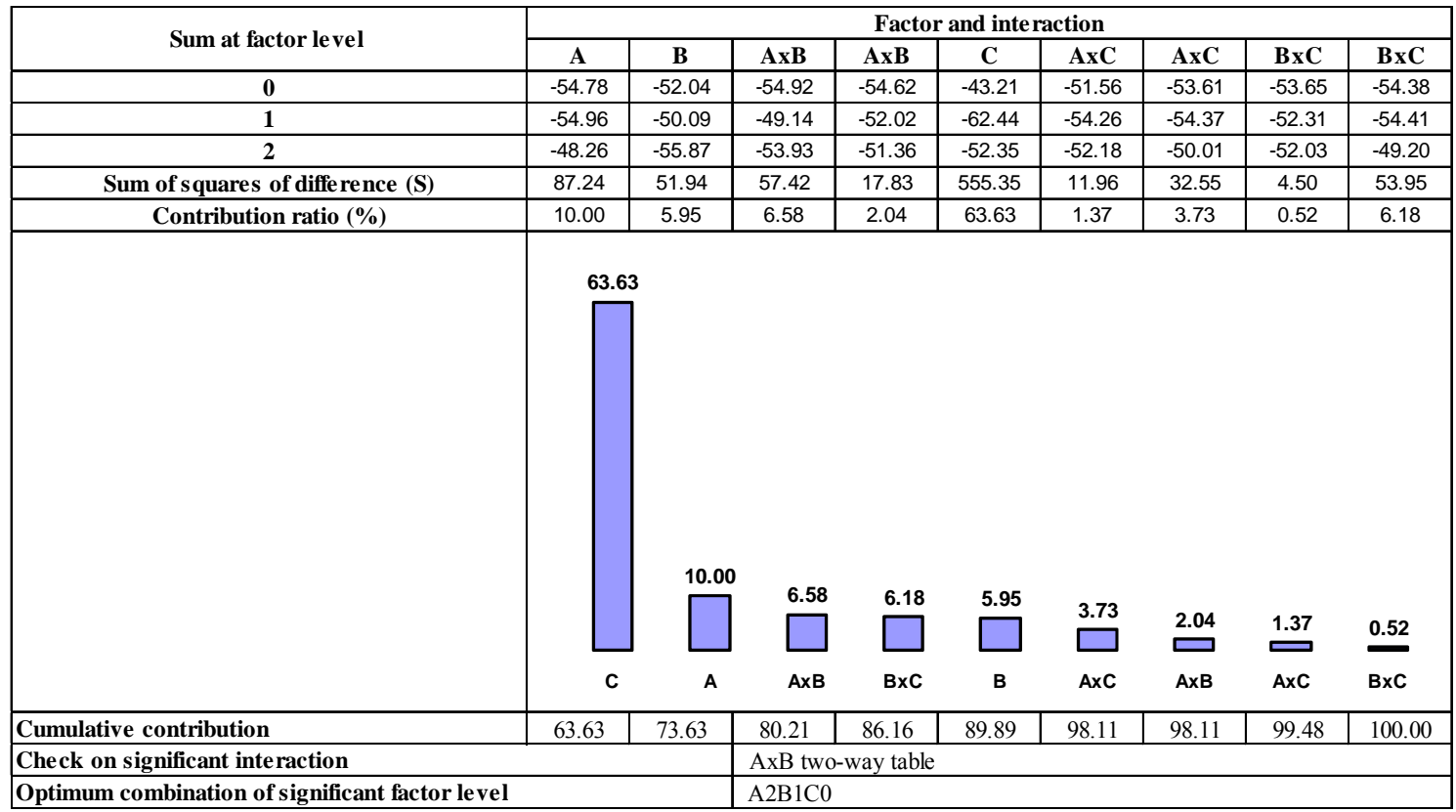

Table 9: Response Table for Mean S/N Ratio for Surface Roughness, and Significant Interaction

\begin{tabular}{lcrrrr}
\hline \hline & & \multicolumn{3}{c}{ Mean S/N ratio } \\
\cline { 3 - 6 } Input parameters & Symbol & Level 0 & Level 1 & Level 2 & Max-Min \\
\hline Cooling method & $\mathrm{A}$ & -6.09 & -6.11 & -5.36 & 0.74 \\
Blank size & $\mathrm{B}$ & -5.78 & -5.57 & -6.21 & 0.64 \\
Work material & $\mathrm{C}$ & -4.80 & -6.94 & -5.82 & 2.14 \\
Interaction AxB & $\mathrm{AxB}$ & -6.10 & -5.46 & -5.99 & 0.64 \\
\hline \hline
\end{tabular}




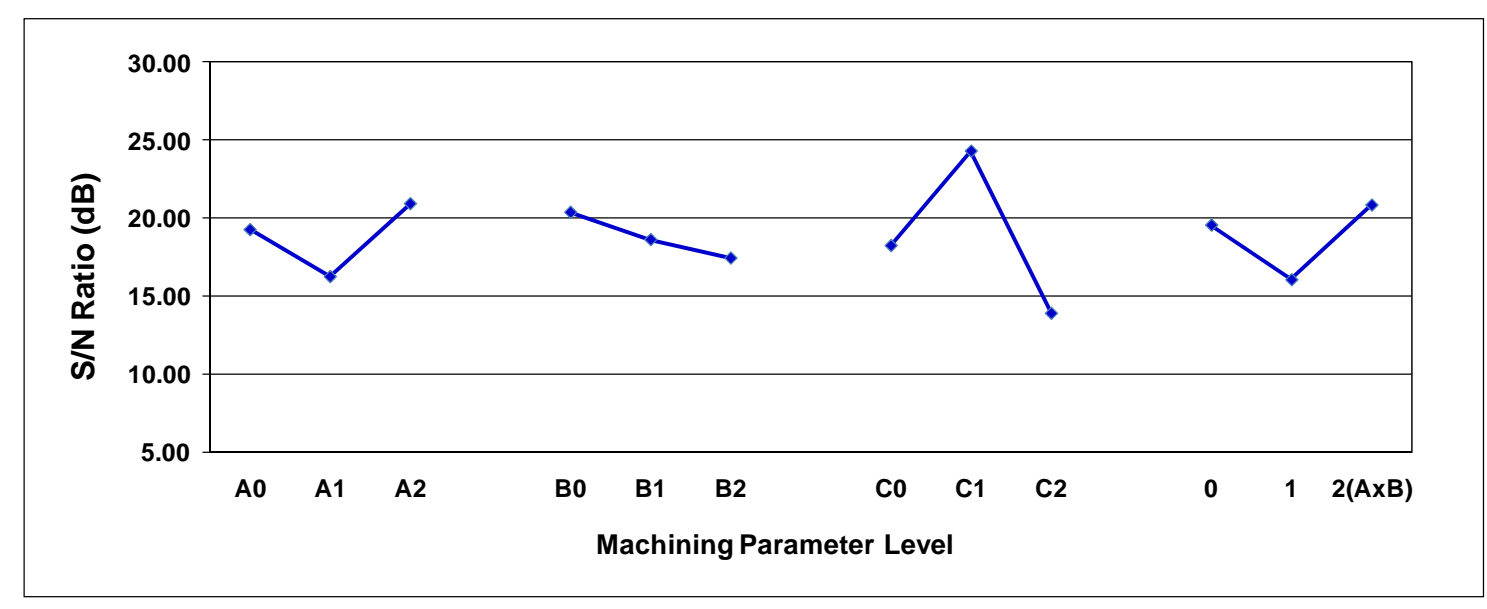

Figure 1: Response graphs of mean and $\mathrm{S} / \mathrm{N}$ ratio for diameter error

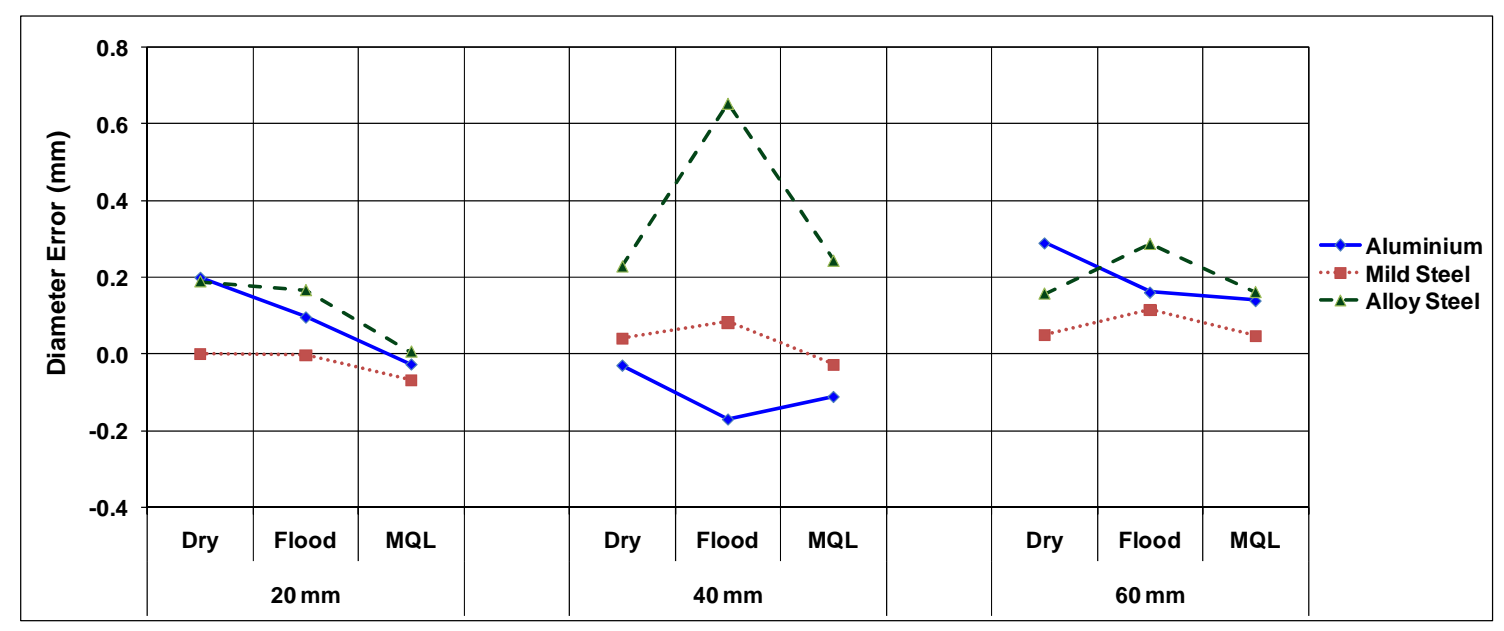

Figure 2: Variation of diameter error for three additional parameters

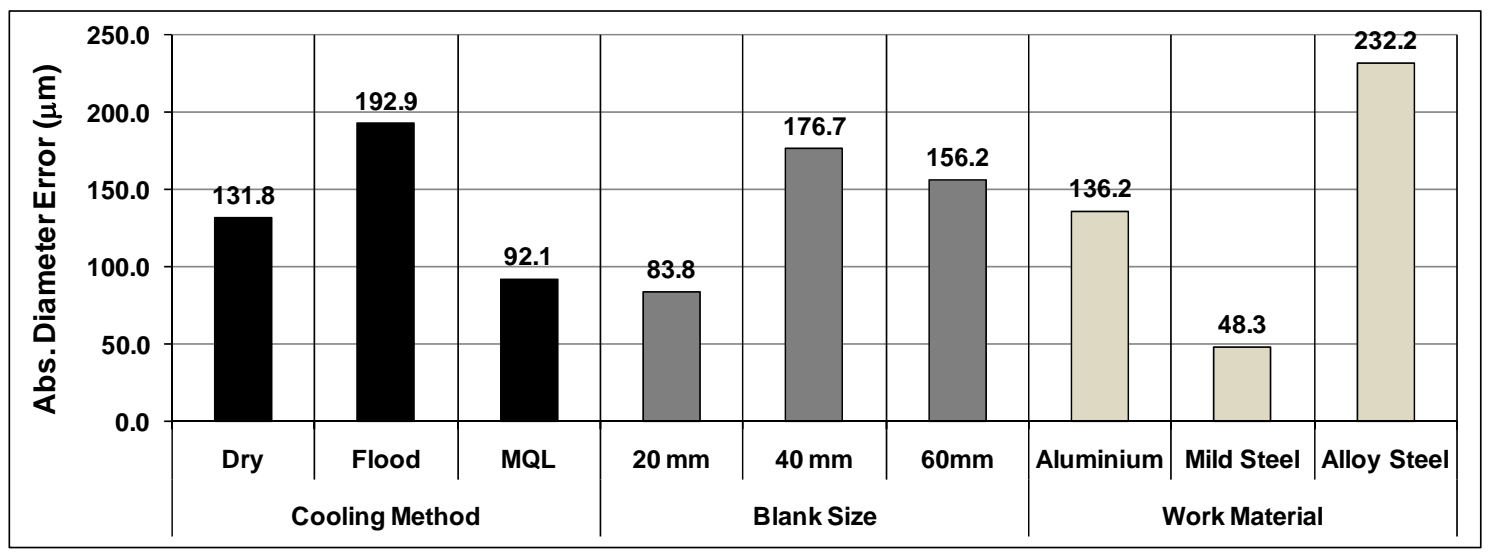

Figure 3: Average variation of diameter error for three additional parameters 


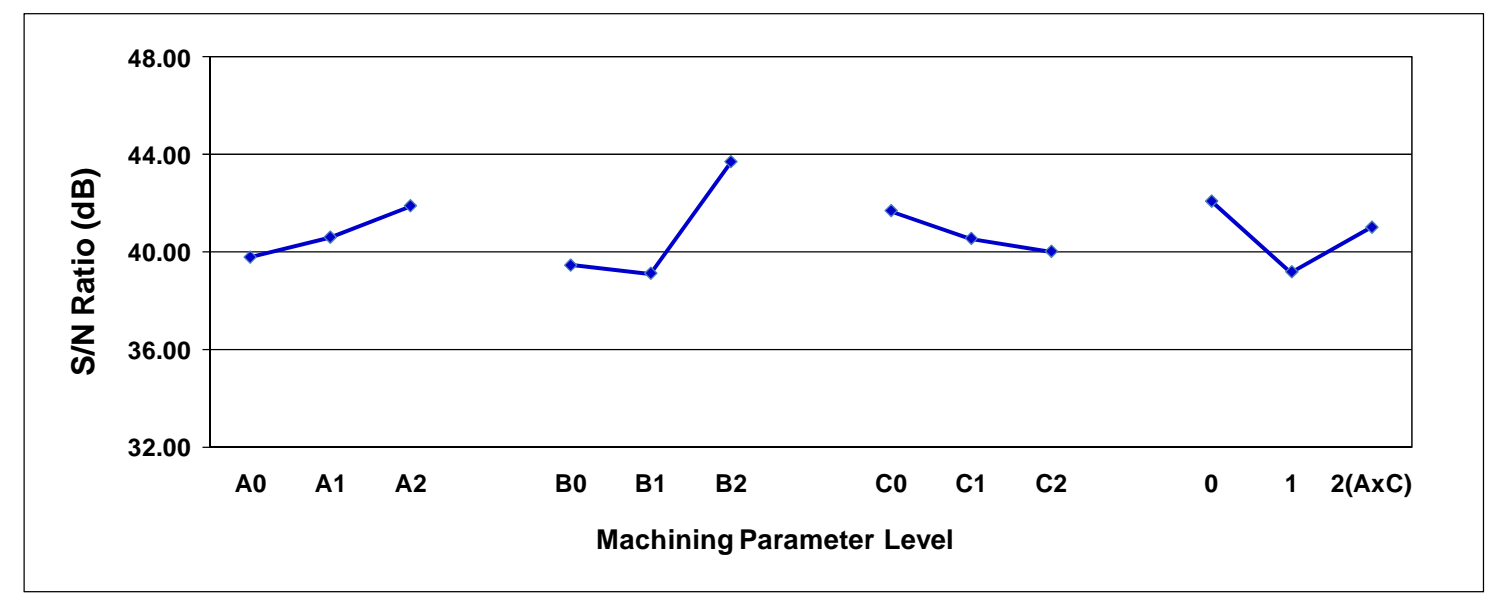

Figure 4: Response graphs of mean and $\mathrm{S} / \mathrm{N}$ ratio for circularity

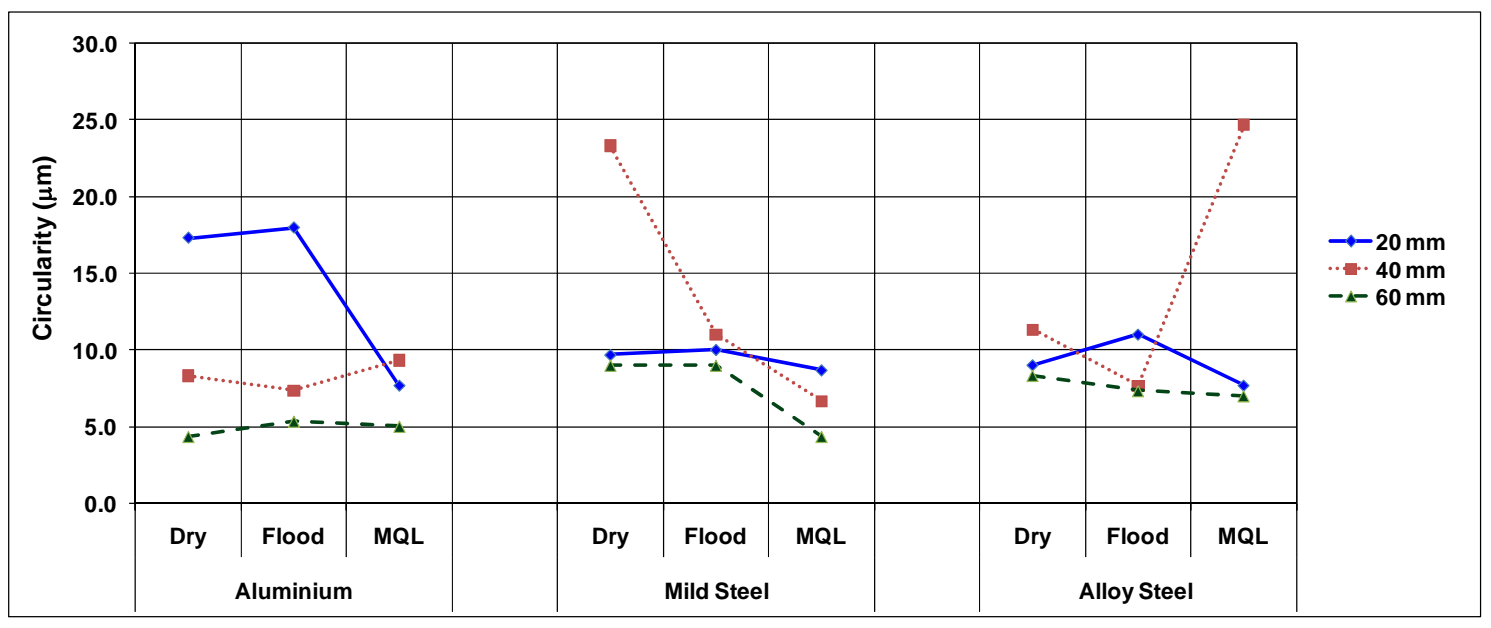

Figure 5: Variation of circularity for additional parameters

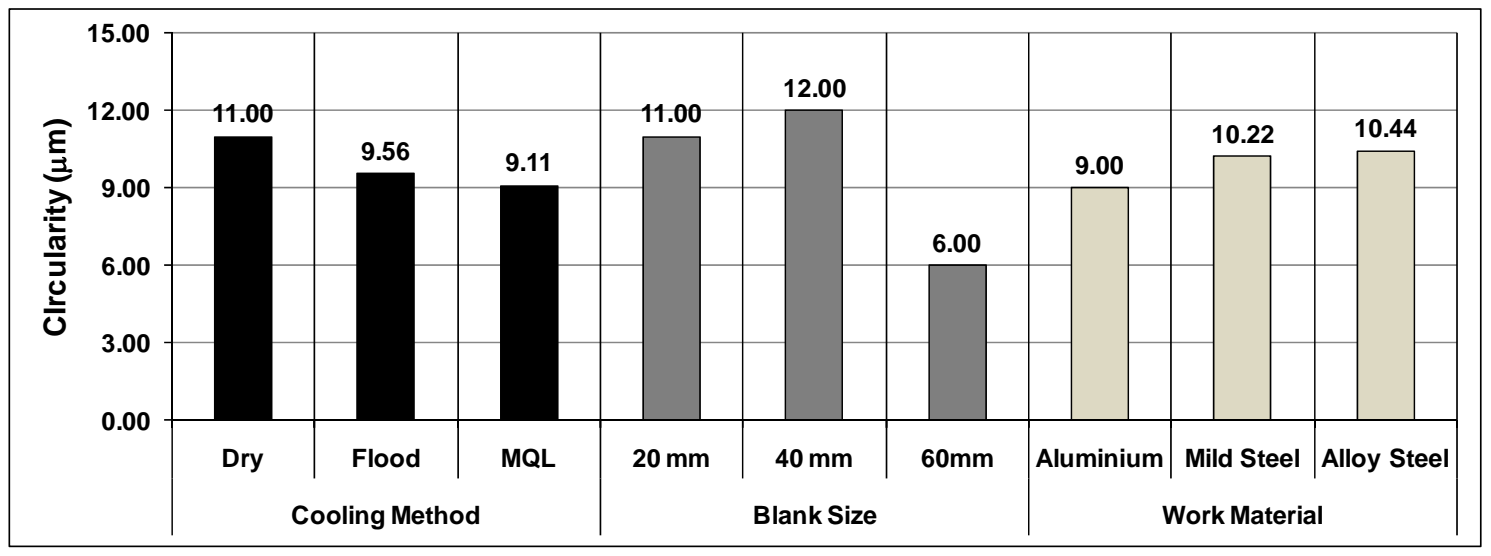

Figure 6: Average variation of circularity for three additional parameters 


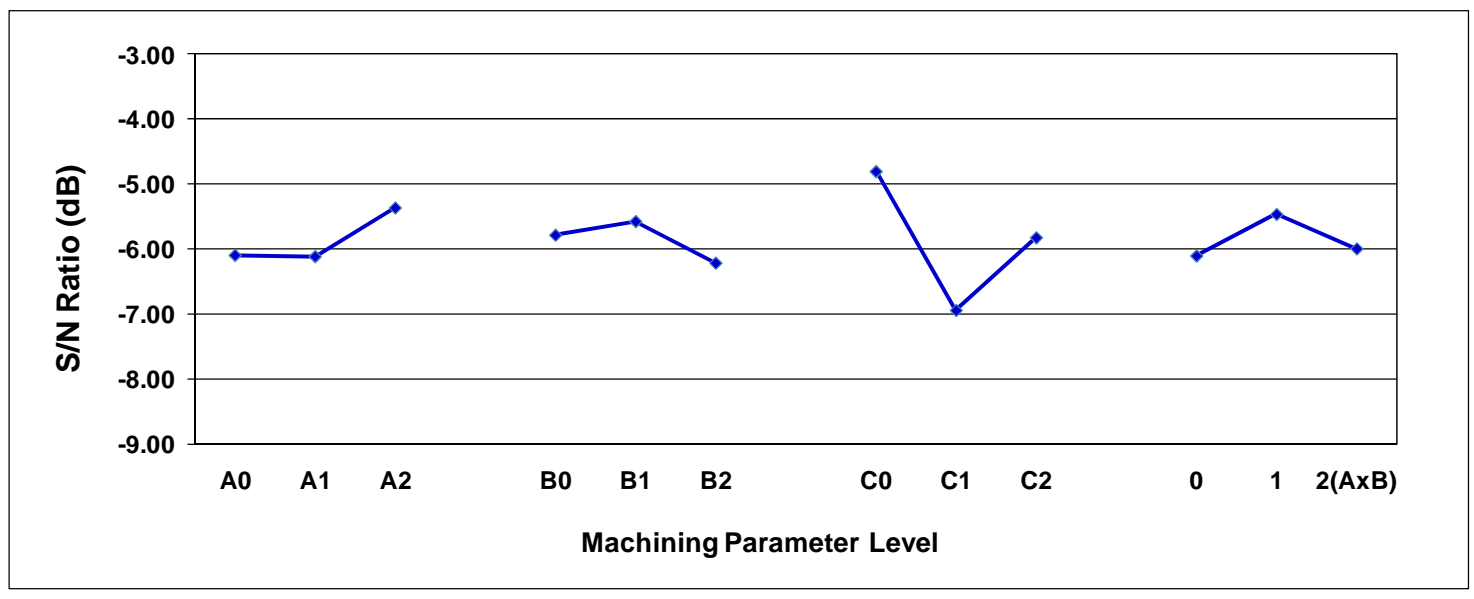

Figure 7: Response graphs of mean and $\mathrm{S} / \mathrm{N}$ ratio for surface roughness

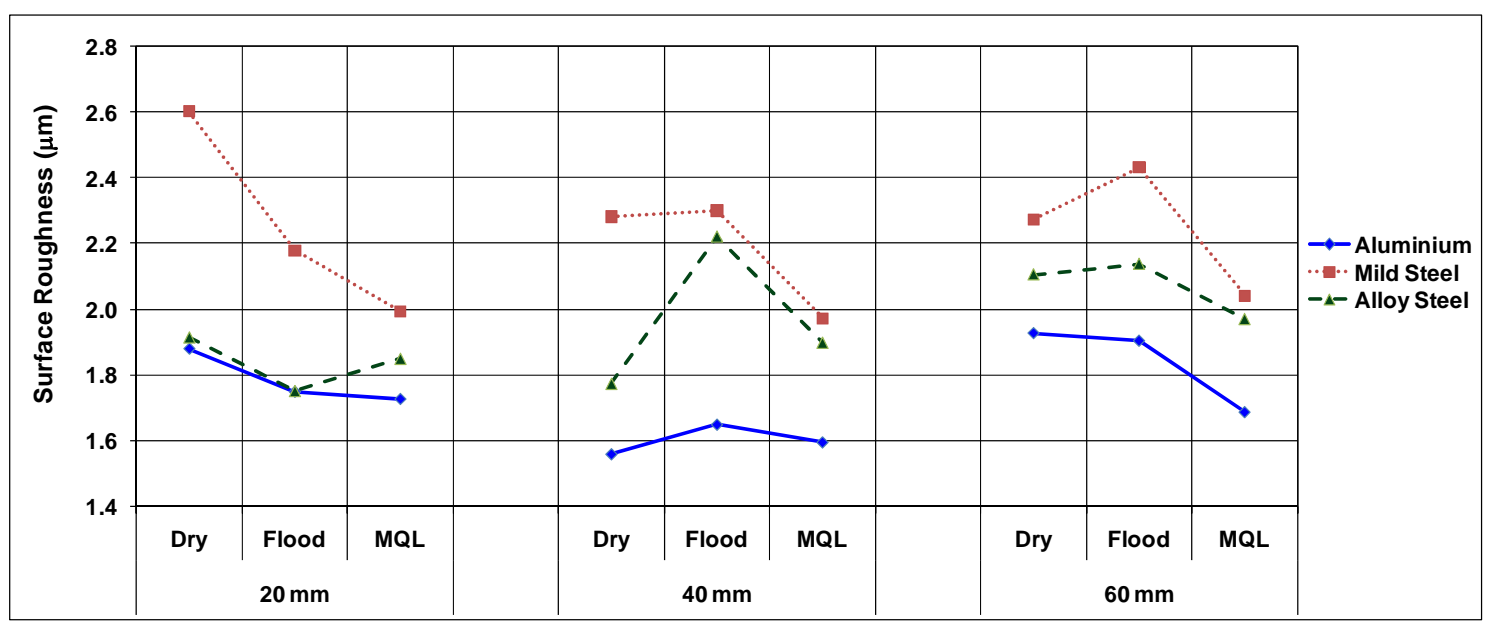

Figure 8: Variation of surface roughness for additional parameters

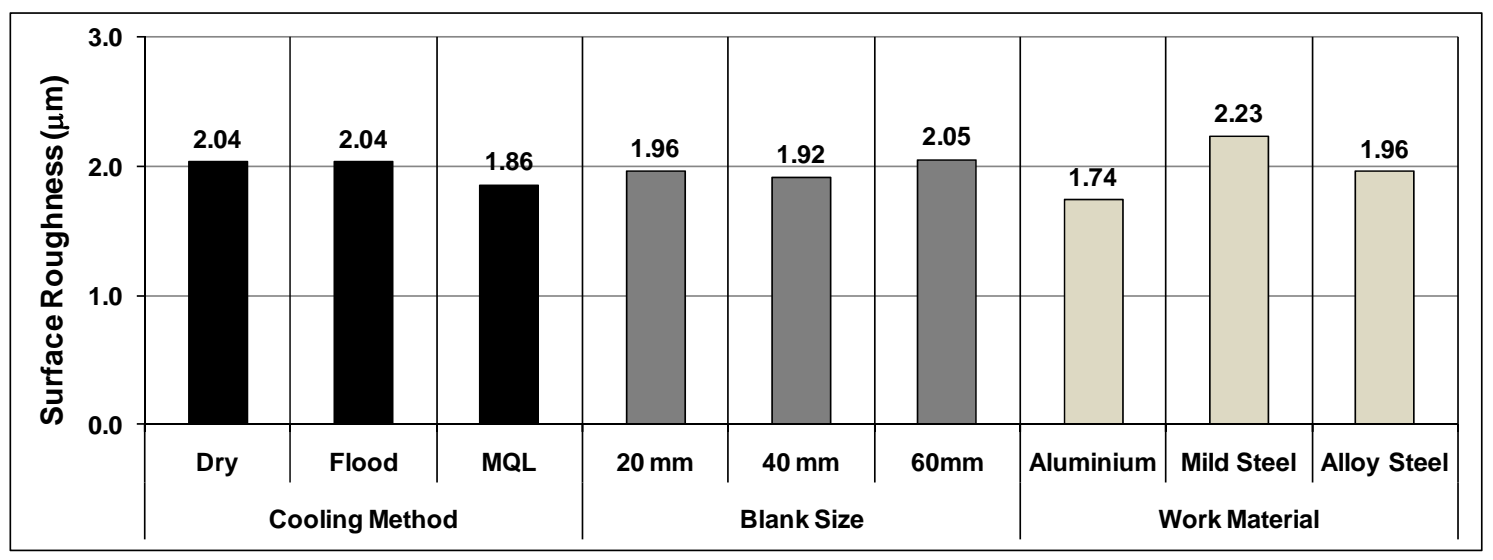

Figure 9: Average variation of surface roughness for three additional parameters 